\title{
Eksperimentasi Model Auditory, Intellectualy, Repetition (AIR) Berbantu LKPD Ditinjau Dari Kecerdasan Matematis Logis
}

\author{
Apri Wahyudi, Evi Gusliana, Abdul Hamid \\ STIT Pringsewu \\ apriwahyudistitpringsewu@gmail.com, Ardnac01@yaoo.com,hamidstai@yahoo.co.id
}

\begin{abstract}
Abstrak
Penelitian ini memiliki tujuan untuk mengetahui: (1) Pengaruh penerapan model pembelajaaran Auditory, Intellectualy, Repetition (AIR) berbantu LKPD terhadap prestasi belajar siswa; (2) Pengaruh masing-masing kecerdasan matematis logis (tinggi, sedang, rendah) terhadap prestasi belajar siswa; (3) Apakah terdapat interaksi antara model pembelajaran Auditory, Intellectualy, Repetition (AIR) berbantu LKPD dan kecerdasan matematis logis yang terjadi pada prestasi belajarnya. Untuk memperoleh jawaban beberapa tujuan penelitian tersebut, maka metode kuantitatif dengan jenis penelitiannya quasi experimental design dipilih dan ujinya adalah analisis variansi (anava) dua jalan kemudian dilanjutkan dengan uji sceffe jika diperlukan. Prestasi dalam penelitian ialah: (1) terdapat pengaruh pengaruh model pembelajaran Auditory, Intellectualy, Repetition (AIR) berbantu LKPD terhadap prestasi belajar siswa; (2) terdapat pengaruh kecerdasan matematis logis terhadap prestasi belajar siswa; (3) tidak terdapat interaksi antara pembelajaran Auditory, Intellectualy, Repetition (AIR) berbantu LKPD yang diterapkan dan masing-masing kategori kecerdasan matematis logis pada prestasi belajar.
\end{abstract}

Kata Kunci: Auditory, Intellectualy, Repetition(AIR) berbantu LKPD, KecerdasanMatematis logis, PrestasiBelajar.

\begin{abstract}
This study aims to determine: (1) the effect of the application of LKPD assisted Auditory, Intellectual, Repetition (AIR) learning models on student learning outcome; (2) The influence of each logical mathematical intelligence (high, medium, low) on student achievement; (3) Is there an interaction between LKPD assisted Auditory, Intellectual, Repetition (AIR) learning models and logical mathematical intelligence that occurs in their learning outcome. To obtain answers to some of the objectives of the study, quantitative methods with quasi experimental design were selected and the test was a two-way (Anava) variance analysis then followed by a sceffe test if needed. Achievements in the study are: (1) there is an influence of the influence of LKPD assisted Auditory, Intellectualy, Repetition (AIR) learning models on student learning outcome; (2) there is the influence of logical mathematical intelligence on student achievement; (3) there is no interaction between LKPD assisted Auditory, Intellectual, Repetition (AIR) learning and each logical mathematical intelligence category on learning outcome.
\end{abstract}

Keyword:LKPD assisted Auditory, Intellectual, Repetition (AIR), Logical Mathematical Intelligence, Learning Outcome. 


\section{A. PENDAHULUAN}

Pendidikan adalah suatu proses yang di dalamnya terdapat proses pembelajaran. Pendidikan merupakan proses yang dilakukan secara sengaja, teratur dan terencana bertujuan mengarahkan dan mengembangkan perilaku peserta didik agar sesuai dengan yang diinginkan (Thaib, 2013). Tujuan pendidikan adalah merubah perilaku peserta didik menjadi sesuai dengan yang diharapakan setelah mengikuti proses belajar mengajar (Purwanto, 2014). Sekolah mempunyai tanggung jawab besar dalam mencapai tujuan pendidikan sesuai dengan pengertian pendidikan dan tujuan pendidikan.

Pada pembelajaran matematika, guru harus pandai memilih metode yang tepat agar tujuan pembelajaran tercapai dengan baik, siswa dapat menyerap pengetahuan dan pemahaman yang diberikan guru (Choirudin, 2017). Berdasarkan hasil wawancara terhadap guru bidang studi matematika Kelas V SDN 2 Metro Utara Tahun Pelajaran 2017/2018. Nilai Kriteria Ketuntasan Minimal (KKM) adalah 70 diperoleh data sebagai berikut:

Tabel 1. Data Hasil Nilai Ulangan Harian Matematika

\begin{tabular}{cccc}
\hline Nilai & Kriteria & Jumlah & Presentase \\
\hline$\geq 70$ & Tuntas & 27 & $37,50 \%$ \\
$<70$ & Tidak & 45 & $62,50 \%$ \\
& Tuntas & 72 & $100 \%$ \\
\hline \multicolumn{2}{c}{ Jumlah }
\end{tabular}

Rendahnya hasil belajar matematika dibenarkan oleh guru bidang studi matematika di SDN 2 Metro Utarayang menyatakan bahwa: Rendahnya hasil belajar siswa karena siswa menganggap matematika termasuk pelajaran yang sulit dan membosankan, kurangnya perhatian siswa terhadap penjelasan guru, dan lemahnya tingkat pemahaman siswa.

Pemahaman siswa juga dipengaruhi oleh 8 jenis kecerdasan salah satunya yaitu kecerdasan matematis logis. "According to Gardner, logical mathematical intelligence is the ability to use numbers effectively, to reason well and to recognize and solve problems using logical patterns"(Arani, 2012)yang berarti menurut Gardner, kecerdasan logis matematis adalah kemampuan untuk menggunakan angka secara efektif, beralasan dengan baik dan mengenali dan memecahkan masalah dengan menggunakan pola logis. Oleh karena itu, penting bagi peserta didik dapat menguasai kecerdasan matematis logis terlebih dalam pembelajaran matematika yang materi pembelajarannya banyak disajikan dalam bentuk angka, logika, penalaran dan berfikir kritis.

Logical-Mathematical intelligence It is the ability to concentrate on mathematical problems, hypotheses and to think logically. Scientists, accountants, engineers, computer programmers, researchers all have a high level of this intelligence (Gangadevi and Ravi, 2014) Diartikan bahwa kecerdasan matematis logis adalah kemampuan untuk berkonsentrasi pada masalah matematika, hipotesis dan berfikir logis. Ilmuwan, akuntan, insinyur, programer komputer, peneliti semua memiliki tingkat kecerdasan yang tinggi.Selain itu, ada kemungkinan peserta didik yang memiliki kecerdasan matematis logis tinggi, sedang dan rendah.Kecerdasan ini berhubungan dengan keterampilan peserta didik dalam melakukan operasi matematis.

Selama ini, dalam proses pembelajaran, guru sebenarnya sudah memperhatikan tingkat kecerdasan yang dimiliki oleh peserta didik, namun guru lebih cenderung untuk segera menyelesaikan materi pembelajaran, sehingga peserta didik dengan tingkat kecerdasan yang rendah akan sering tertinggal dalam pembelajaran (Anwar, 2015). Pembelajaran yang monoton dari waktu ke waktu menyebabkan peserta didik merasa bosan dan tidak tertarik untuk belajar terlebih dalam pelajaraan matematika. Metode atau model pembelajaran matematika yang umumnya digunakan oleh guru matematika adalah metode konvensional salah satunya model pembelajaran langsung dimana guru lebih mengandalkan metode berceramah dan papan tulis dijadikan sebagai alat bantu utama dalam proses pembelajaran, sehingga peserta didik menjadi cenderung pasif dan kurang berpartisipasi dalam proses pembelajaran. Untuk itu diperlukan suatu model pembelajaran yang tepat, model pembelajaran yang ditawarkan adalah Model Pembelajaran AIR berbantuan LKPD.

AIR adalah modelpembelajaran yang dipilih peneliti sebagai salah satu upaya untuk meningkatkan kemampuan matematika peserta didik terutama dalam pencapaian prestasi belajar matematika pada materi pokok Aritmatika Sosial secara optimal. Model pembelajaran AIR terdiri dari tiga aspek Auditory, Intellectual and Repetition(Asih and Nilakusumawati 2017), yaitu:(a) Auditory, dipelajari dengan berbicara 
dan mendengarkan, mendengarkan, presentasi, argumentasi, menyatakan pendapat, dan menanggapi. Guru harus dapat mengondisikan siswa untuk mengoptimalkan indera telinga, sehingga hubungan antara telinga dan otak dapat digunakan secara optimal. Salah satu kegiatan yang dapat mendukung pendengaran adalah membentuk siswa menjadi beberapa kelompok dan kemudian setiap kelompok diminta untuk menunjukkan hasil diskusi secara bergantian.Dalam presentasi, ada kelompok yang berbicara dan ada juga kelompok yang mendengarkan, jadi pendengaran dilaksanakan; (b) Intelektual, kegiatan internal pikiran siswa ketika mereka menggunakan kecerdasan untuk merefleksikan pengalaman mereka. (c) Repetation, pengulangan diperlukan dalam pembelajaran, sehingga pemahaman yang lebih dalam dan lebih luas.

Ditambah dengan bantuan LKPD yang dibuat diharapkan dapat menjadisarana untuk membantu mempermudah dan meningkatkan aktifitas peserta didik dalam proses kegiatan pembelajaran yang sertameningkatkan prestasi belajar peserta didik terhadap materi Aritmatika sosial. Instrumen LKPD meliputi aspek bahasa, desain dan materi. Aspek bahasa meliputi:1) penggunaan bahasa sesuai dengan EYD, 2) bahasa yang digunakan sesuai dengan tingkat perkembangan kognisi siswa, 3) bahasa yang digunakan komunikatif, 4) kalimat yang digunakan jelas dan mudah dimengerti, 5) kejelasan petujuk atau arahan. Aspek materi meliputi: 1) kejelasan kompetensi inti, kompetensi dasar dan indikator, 2) kesesuaian kompetensi inti dan kompetensi dasar dengan tujuan pembelajaran, 3) ketepatan penjabaran kompetensi dasar ke dalam indikator, 4) kesesuaian indikator dengan tujuan pembelajaran, 5) kesesuaian indikator dengan tingkat perkembangan siswa. Aspek desain meliputi: 1) penyajian materi secara runtut dan sistematis, 2) tulisan menggunakan komposisi ukuran dan jenis huruf yang seimbang, 3) menggunakan cover LKPD yang menarik dan telah disesuaikan, 4) permasalahan yang dibuat menyatakan minat peserta sisik untuk melakukan percobaan serta memberikan gambaran materi yang dipelajari. sajikan:

Berikut contoh LKPD yang peneliti
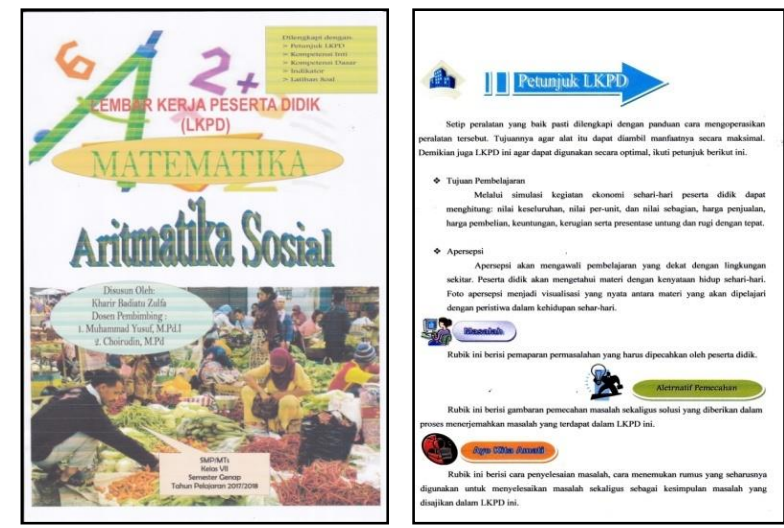

Gambar 1 dan 2 Bagian Cover dan Petunjuk Penggunaan LKPD
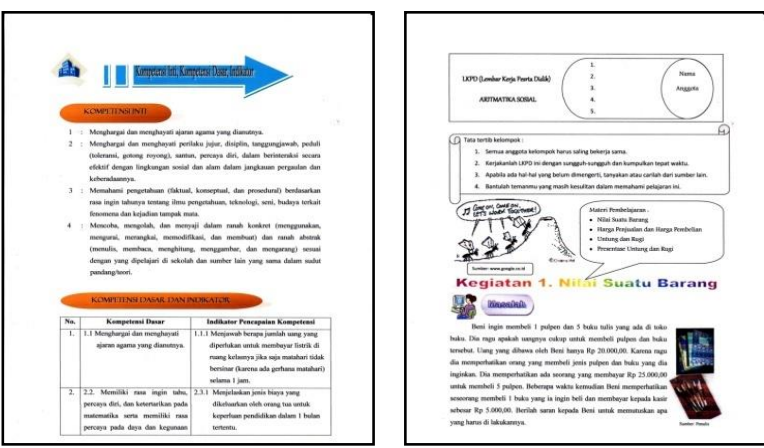

Gambar 3 dan 4. KD, Indikator danLembar Kegiatan

Penelitian tentang model Pembelajaran Auditory Intellectual Repetition (AIR) berbantu LKPD dilakukan oleh (Handayani, I.M, Pujiastuti, E., and Suhito 2014) dengan judul "Keefektifan Model AIR Berbantuan LKPD Terhadap Kemampuan Penalaran Matematis Peserta Didik SMP. Penelitain tersebut memberikan kesimpulan bahwa dengan menggunakan model pembelajaran AIR berbantu LKPD kemampuan penalaran peserta didik pada materi yang diajarkan lebih baik.Peserta didik lebih memahami materi pembelajaran yang diajarkan, serta peserta didik dilatih untuk benar-benar berpikir dan memecahkan masalah.

Penelitian

(Mutlikha,

D.I.

2015)Efektivitas Penggunaan Model

Pembelajaran AIR (Auditory, Intellectualy, Repetition)Terhadap Hasil Belajar Sejarah Siswa. Penelitian tersebut memberikan kesimpulan setelah diberikan perlakuan yaitu menggunakan model pembelajaran AIR hasil belajar peserta didik, aspek afektif dan pada aspek psikomotrik mengalami peningkatan. 
Dewasa ini sudah banyak penelitian dibidang pendidikan yang menyatakan bahwa model-model pembelajaran baru secara signifikan dapat memberikan pengaruh besar terhadap peningkatan kemampuan pemecahan masalah matematika.Namun, hingga saat ini masih banyak para guru belum menerapkan model-model pembelajaran baru tersebut.Dengan pertimbangan inilah yang mendorong penulis untuk meneliti masalah ini.

\section{B. METODE}

Jenis penelitian ini adalah eksperimental semu (quasi eksperimental research) yang melibatkan dua kelompok yaitu kelompok eksperimen dan kelompok kontrol, dengan analisis data menggunakan angka-angka atau penelitian kuantitatif. Kedua kelompok tersebut sama dalam segala segi dan hanya berbeda pada perlakuan pembelajaran yang diberikan. Adanya kesamaan ini ada yang karena diasumsikan, dikondisikan dan ada pula yang harus melalui pengujian dengan statistik uji, yaitu uji keseimbangan rata-rata yang digunakan untuk membuktikan bahwa kedua kelompok dalam keadaan seimbang sebelum perlakuan diberikan.Perlakuan yang diberikan kepada kelompok eksperimen adalah penerapan model pembelajaran AIR berbantu LKPD, sedangkan model konvensional diterapkan kepada kelompok kontrol.Penelitian dilakukan di SDN 2 Metro Utara yang masing-masing diambil kelas V A sebagai kelas kontrol dan kelas V B sebagai kelaseksperimen.Teknik pengumpulan data adalah metode dokumentasi dan metode tes.Instrumen penelitian terdiri atas tes kecerdasan matematis logis dan tes prestasi belajar matematika pada materi Aritmatika Sosial. Untuk instrumen tes prestasi belajar, mengacu pada kriteria yaitu validitas isi, daya pembeda $(\mathrm{D} \geq 0,3)$ tingkat kesukaran $(0,3 \leq \mathrm{P} \leq$ 0,7)dan reliabilitas (r11 $\geq 0,7$ )(Arifin 2016, 254), dari 30 butir soal yang diujicobakan diperoleh 20 butir soal yang digunakan sebagai alat pengambil data prestasi belajar matematika siswa dan 30 butir soal yang diujicobakan diperoleh 20 butir soal yang digunakan sebagai alat pengambil data kecerdasan matematis logis siswa. Uji prasyarat analisis yaitu uji normalitas dengan Lilliefors dan uji homogenitas dengan uji Bartlett. Uji analisis data yang digunakan yaitu analisis variansi dua jalan dengan sel tak sama (Budiyono, 2011).

\section{HASIL DAN PEMBAHASAN}

Penerapan model pembelajaran AIR berbantu LKPD pada kelas eksperimen sebagai berikut:

(1) Di awal guru menyampaikan kompetensi dan garis-garis besar materi

(2) Guru membagi peserta didik menjadi beberapa kelompok kecil yang terdiri dari 4-5 anggota, serta membagikan LKPD kepada setiap kelompok dan memberikan kesempatan bagi peserta didik untuk bertanya mengenai soal dalam LKPD yang kurang dipahami.

(3) Guru membimbing kelompok belajar peserta didik untuk berdiskusi dengan rekan dalam satu kelompok sehingga dapat menyelesaikan LKPD lalu mempresentasikan hasil diskusi.

(4) Setelah selesai berdiskusi, peserta didik dengan pengarahkan dari guru membuat kesimpulan secara lisan tentang materi yang telah dibahas dan mendapat pengulangan materi dengan cara mendapatkan tugas atau kuis untuk tiap individu (repetition).

Setelah siswa mengerti bagaimana menyelesaikan masalah pada harga keseluruhan barang, untung dan rugi serta presentase keuntungan dan kerugian dari berbagai situasi melalui percobaan, guru memberikan tes kepada siswa berupa 20 soal pilihan ganda kecerdasan matematis logis dan 20 soal pilihan gandauntuk melihat prestasi belajar siswa. Soal tersebut sudah diuji tingkat validitas, reliabilitasnya, tingkat kesukaran dan daya beda, dan hasilnya semua soal layak untuk dijadikan alat ukur penelitian.

1. Hipotesis Pertama

Dari anava dua jalan sel tak sama diperoleh $\mathrm{F}_{\mathrm{obs}}=4,64>4,08=\mathrm{F}_{0,05 ; 1 ; 41 . \mathrm{F}_{\mathrm{obs}}}$ masuk daerah kritis sehingga $\mathrm{H}_{0}$ ditolak.Ini berarti model pembelajaran memberikan efek yang berbeda terhadap prestasi belajar matematika siswa pada pokok bahasan aritmatika sosial. Karena rerata baris $\mathrm{a}_{1}=$ $173,95>161,96=a_{2}$, Maka dapat disimpulkan bahwa Model Pembelajaran AIR berbantu LKPD menghasilkan prestasi belajar matematika yang lebih baik dari pada model pembelajaran langsung pada pokok bahasan aritmatika sosial. Ini berarti hipotesis pertama diterima. 
Pada saat proses pembelajaran mengajarkan materi aritmatika sosial menggunakan model pembelajaran AIR berbantu LKPD terlebih dahulu peneliti mengenalkan apa saja yang termasuk dalam aritmatika sosial di kehidupan sehari-hari mereka.Setelah itu siswa tidak hanya duduk, mendengarkan dan mengerjakan soal tetapi siswa juga ikut dalam memecahkan suatu masalah dengan diskusi kelompok dan mempresentasikannya di depan kelas. Menggunakan model pembelajaran ini siswa juga lebih aktif bertanya karena rasa penasaran siswa dengan masalah yang dikaitkan pada kehidupan sehari-hari tentang aritmatika sosial, dengan mengaitkan masalah pada kehidupan seharihari siswa lebih mudah dalam memecahkan suatu masalah dengan caranya sendiri.

Peneliti meminta siswa untuk membentuk kelompok satu kelompok terdiri dari 5-6 oranguntuk mendiskusikan jawaban, karena siswa menemukan jawaban dengan caranya sendiri maka setiap siswa lebih percaya diri dalam membandingkan sekaligus mendiskusikan jawaban yang ada di LKPD dalam satu kelompoknya. Dari hal tersebut terlihat bahwa model pembelajaran AIR berbantu LKPD memberikan efek yang berbeda terhadap proses belajar matematika siswa pada pokok bahasan aritmatika sosial.

2. Hipotesiskedua

\section{Dari}

anavaduajalanseltaksamadiperoleh $\quad \mathrm{F}_{\mathrm{obs}}=$

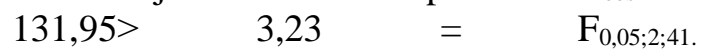
$\mathrm{F}_{\text {obs }}$ masukdaerahkritiksehingga

$\mathrm{H}_{0}$ ditolak.Iniberartisemuakategorikecerdasa nmatematislogissiswamemberikanefek yang berbedaterhadapprestasibelajarmatematikasi swa.Karenapadahipotesiskedua $\mathrm{H}_{0}$ ditolakmakadiperlukanujilanjutpascaanavad enganmenggunakanmetodeScheffe.

Dari perhitungan dengan menggunakan metode Scheffe diperoleh hasil bahwa pada tingkat kecerdasan matematis logis tinggi dan sedang $\mathrm{F}_{\mathrm{obs}}=$ $241,43>6,46=2 \mathrm{~F}_{0,05 ; 2 ; 41} \mathrm{~F}_{\text {obs }}$ masuk daerah kritik sehingga $\quad \mathrm{H}_{0}$ ditolak. Sedangkanpadatingkatkecerdasanmatematisl ogistinggidanrendah $\mathrm{F}_{\mathrm{obs}}=1445,13>6,46=$ $2 \mathrm{~F}_{0,05 ; 2 ; 41} \mathrm{~F}_{\text {obs }}$ masukdaerahkritiksehingga

$\mathrm{H}_{0}$ ditolak.

Dan

padatingkatkecerdasanmatematislogissedang danrendah $\mathrm{F}_{\mathrm{obs}}=309,22>6,46=2 \mathrm{~F}_{0,05 ; 2 ; 41}$ $\mathrm{F}_{\mathrm{obs}}$ masukdaerahkritiksehingga $\mathrm{H}_{0}$ ditolak.
Karena rerata pada tingkat kecerdasan matematis logis tinggi $=147,95>113,75=$ tingkat kecerdasan matematis logis sedang dan tingkat kecerdasan matematis logis tinggi $=147,95>74,21=$ tingkat kecerdasan matematis logis rendah maka dapat disimpulkan bahwa pada setiap kategori tingkat kecerdasan matematis logis matematika tinggi menghasilkan prestasi belajar yang lebih baik dari pada tingkat kecerdasan matematis logis sedang dan rendah.

Sedangkanpadatingkatkecerdasanmatematisl ogissedangdanrendahmemberikanefek yang samaterhadapprestasibelajarmatematikasisw apadapokokbahasanaritmatikasosial.

Dalam kegiatan pembelajaran siswa yang memiliki kecerdasan matematis logis tinggi saat pembelajaranakan di mulai terlihat lebih siap dari siswa yang memiliki kecerdasan matematis logis sedang dan rendah. Setelah guru memberikan masalah yang berkaitan dengan kehidupan seharihari untuk dipecahkan oleh siswa dengan caranya sendiri, siswa yang memiliki kecerdasan matematis logis tinggi cenderung diam karena dengan mudah dapat menemukan solusi dari masalah tersebut dengan caranya sendiri, sedangkan siswa yang memiliki kecerdasan matematis logis sedang dan rendah cenderung aktif bertanya mengenai apa maksud dari maslah tersebut dari situ terlihat bahwa siswa yang memiliki kecerdasan matematis logis sedang dan rendah lambat dalam memahami suatu masalah sehingga siswa kesulitan dalam memecahkan masalah tersebut. Dapat disimpulkan bahwa semua kategori kecerdasan matematis logis siswa memberikan efek yang berbeda terhadap prestasi belajar matematika siswa(Ningsih, E. F. 2017).

3. Hipotesis Ketiga

Dari anava dua jalan sel tak sama diperoleh $\mathrm{F}_{\mathrm{obs}}=0,37<3,23=\mathrm{F}_{0,05 ; 2 ; 41} . \mathrm{F}_{\mathrm{obs}}$ tidak masuk daerah kritik sehingga $\mathrm{H}_{0}$ diterima.Ini berarti tidak ada interaksi antara model pembelajaran dengan kecerdasan matematis logis matematika siswa. Karena pada tiap kategori kecerdasan matematis logis baik tinggi, sedang ataupun rendah model pembelajaran AIR berbantu LKPD selalu lebih baik dari pada model pembelajaran langsung, ini berarti untuk 
masing-masing model pembelajaran memberikan efek yang berbeda pada masing-masing tingkat kecerdasan matematis logis. Sehingga bisa disimpulkan bahwa tidak ada interaksi antara model pembelajaran dengan kecerdasan matematis logis siswa pada pokok bahasan aritmatika sosial.

Dalam kegiatan pembelajaran di kelas, siswa yang diajar dengan menggunakan model pembelajaran AIR berbantu LKPD dan pembelajaran langsung serta mempunyai kecerdasan matematis logis kategori tinggi tidak selalu mempunyai nilai prestasi belajar yang tinggi, begitu pula dengan siswa yang diajar dengan menggunakan model pembelajaran AIR berbantu LKPD dan mempunyai kecerdasan matematis logis kategori sedang dan rendah. Ada beberapa siswa yang suka belajar dengan mengaitkan suatu masalah pada kehidupan sehari-hari, menggunakan alternatif pemecahan masalah yang terdapat dalam LKPD, dapat membantu menemukan solusi atau jawaban dari masalah dengan caranya sendiri, dan dari hasil tes kecerdasan matematis logis yang diberikan, siswa tersebut mempunyai hasil kecerdasan matematis logis tinggi. Akan tetapi setelah diberikan tes prestasi belajar, siswa tersebut mendapatkan hasil dengan kategori sedang bahkan rendah. Begitupun sebaliknya, ada beberapa siswa yang tidak suka belajar dengan mengaitkan suatu masalah pada kehidupan sehari-hari, kurang tertarik dengan alternatif pemecahan masalah dalam LKPD, kurang mampu menemukan solusi atau jawaban dari masalah dengan caranya sendiri, dan dari hasil tes kecerdasan matematis logis yang diberikan, beberapa siswa tersebut mempunyai hasil kecerdasan matematis logis tersebut mendapatkan hasil dengan kategori tinggi. Sehingga bisa disimpulkan bahwa tidak ada interaksi antara model pembelajaran dengan kecerdasan matematis logis siswa (Widyawati, Mardiyana, and Iswahyudi 2014).

\section{KESIMPULAN}

Berdasarkan hasil penelitian dan analisis data yang telah dilakukan, maka dapat disimpulkan sebagai berikut:
1. Siswa yang diajar menggunakan model pembelajaran AIR berbantu LKPD memiliki prestasi belajar matematika lebih baik daripada siswa yang diajar menggunakan model pembelajaran langsung.

2. Prestasi belajar siswa dengan kecerdasan matematis logis tinggi lebih baik daripada siswa dengan kecerdasan matematis logis sedang. Dan siswa dengan kecerdasan matematis logis tinggi lebih baik daripada siswa dengan kecerdasan matematis logis rendah. Dan siswa dengan kecerdasan matematis logis sedang lebih baik daripada siswa dengan kecerdasan matematis logis rendah.

3. Tidak terdapat interaksi antara model pembelajaran AIR berbantu LKPD dengan kecerdasan matematis logis matematika terhadap prestasi belajar matematika materi pokok aritmatika sosial siswa.

\section{DAFTAR PUSTAKA}

Anwar, Muhammad Saidun. 2015. "Efektifitas Pembelajaran PBL (Problem Based Learning) Terhadap Kemampuan Berpikir Kritis Dan Kreatif Siswa Materi Tiga Dimensi." Masters, Universitas Terbuka. http://repository.ut.ac.id/6912/.

Arani, Hossein Khani. 2012. "Metacognitive Strategies and Logical/Mathematical Intelligences in EFL Context: Investigating Possible Relationships', Theory and Practice in Language Studies." Academy Publisher Manufactured In Finland 2 (2).

Arifin, Zainal. 2016. Evaluasi Pembelajaran. Bandung: Remaja Rosdakarya.

Asih, Ni Made, and Putu Eka Nilakusumawati. 2017. "Effectiveness Application of Auditory Intellectually Repetition (AIR) Learning Model To Improve Student's Learning Outcomes on Subject TwoDimensional And Three-Dimensional Shapes." International Journal of Advanced Research (IJAR).

Budiyono. 2011. Penilaian Hasil Belajar. Surakarta: Program Pascasarjana UNS.

Choirudin, Choirudin. 2017. "Efektivitas Pembelajaran Berbasis Schoology." NUMERICAL: Jurnal Matematika Dan Pendidikan Matematika, December, 101-26. 
https://doi.org/10.25217/numerical.v1i2. 131.

Gangadevi, and Ravi. 2014. "Multiple Intelligence Based Curriculum To Enhance Inclusive Education To Bring Out Human Potential." International Journal of Advanced Research, Tamilnadu: College of Education Coimbatore 2 (8).

Handayani, I.M, Pujiastuti, E., and Suhito. 2014. "Keefektifan Auditory Intellectually Repetition Berbantuan LKPD Terhadap Kemampuan Penalaran Peserta Didik SMP.” Kreano: Jurnal Matematika Kreatif-Inovatif 5 (1).

Mutlikha, D.I. 2015. "Efektivitas Penggunaan Model Pembelajaran AIR (Auditory, Intellectualy, Repetition)Terhadap Hasil Belajar Sejarah Siswa Kelas XI SMA Negeri 2 Kota Tegal Tahun Pelajaran 2015/2016." Semarang: Universitas Negeri Semarang.

Ningsih, E. F. 2017. "Proses Berpikir Mahasiswa Dalam Pemecahan Masalah Aplikasi Integral Ditinjau Dari Kecemasan Belajar Matematika (Math Anxiety)." Iqra (Educational Journal) 1 (2): 191-217.

Purwanto. 2014. Evaluasi Hasil Belajar. Jakarta: Pustaka Pelajar.

Thaib, Eva Nauli. 2013. "Hubungan Antara Prestasi Belajar Dengan Kecerdasan Emosional." Jurnal Ilmiah DIDAKTIKA XIII (2).

Widyawati, Santi, Mardiyana, and Gatut Iswahyudi. 2014. "Eksperimentasi Model Pembelajaran Kooperatif Tipe Two Stay Two Stray (TSTS) Dan Numbered Heads Together (NHT) Ditinjau Dari Kecerdasan Majemuk Peserta Didik." Jurnal Elektronik Pembelajaran Matematika 2 (9): 972 83. 